DL Revista Humanismo

N 10 y Sociedad

\title{
El sentido ético y las facultades de derecho: la ética como expresión del deber ${ }^{ \pm}$
}

The sense of ethics in a law school: ethics as an expression of duty

\section{José Luis Chaves-López ${ }^{1 *}$}

${ }^{1}$ Doctor en Derecho Canónico; Docente Filosofía - Ética profesional Jurídica - Derecho y Humanidades. Grupo de Investigación Henry Dunant. Línea del proyecto: Derechos Humanos. Nombre proyecto: el cambio del sentido ético en los estudiantes de derecho: Origen, causas, consecuencias e implicaciones.

(Recibido: 6 de mayo de 2013; Aceptado: 24 de junio de 2014).

\section{Resumen}

En la primera parte de esta investigación presentada en la Revista Institucional RHS-Revista Humanismo y Sociedad (2013) mostrábamos cómo los cambios en la manera de vivir los principios y los valores ya no como verdades absolutas sino como algo relativo, ha llevado a la sociedad a considerar que es normal modificar criterios y paradigmas ateniéndose a criterios personales o conveniencias sociales. Esta segunda etapa de la investigación la intención está dirigida a descubrir cómo los estudiantes del programa de Derecho, objeto de nuestro estudio, asumen las acciones contrarias a los principios éticos y las hacen parte de su vida personal y académica, pues en su vivencia ética no hay distinción entre lo cotidiano y lo académico. El enfoque, para esta parte de la investigación, estará determinado por la acepción del término ética en cuanto deber y la forma como los estudiantes relacionan o separan las connotaciones que para su vida profesional esto implica. La fuente que continuaremos utilizando son los talleres que se trabajaron con los estudiantes en la cátedra de Ética profesional jurídica. Analizamos las diversas respuestas desde el punto de vista del deber y la manera como ellos lo asumen.

Palabras clave: deber, deberes, ética, obligaciones, sentido ético.

\section{Abstract}

The first part of this study, published in RHS-Revista Humanismo y Sociedad (2013) journal, showed how changes in the way we live principles and values as relative truths has led us to modify criteria and paradigms according to personal criteria or social conventions. This second part of the study aimed to discover how law students act counter to ethical principles incorporating that behavior into their personal and academic life, because in their ethic experience

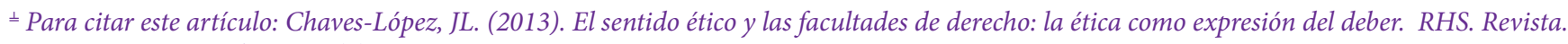
Humanismo. Soc, Volumen 2 (1): 26-32.

* Autor para correspondencia: José Luis Chaves-López. Institución Universitaria - CESMAG. Año 2013 - Primer semestre académico. E-mail: jlchavez@iucesmag.edu.co
}

Revista. Humanismo.Soc. 2014; Volumen 2: 26-32. 
there is no distinction between everyday life and the academy. This study focuses on how students accept the term ethics as duty, and how they relate or separate its connotations in their professional conduct. The information was obtained from student workshops conducted in Legal professional ethics class. This study analyzed student responses from the standpoint of duty and how they take it.

Key words: duty, duties, ethics, liability, ethical sense.

\section{Metodología}

Como lo mencionamos en el aparte Introducción, los resultados obtenidos provienen de los talleres desarrollados con los estudiantes en la cátedra de Ética profesional jurídica.

Para tener un punto de comparación sobre el material recabado en la primera parte se amplió el proceso de entrevista a los docentes recién vinculados al programa de Derecho, para tener una visón lo más objetiva posible sobre su experiencia de la relación entre lo académico y lo ético y la manera cómo perciben las actitudes de sus estudiantes y su sentir sobre las conductas contrarias a los principios éticos.

La información se analiza desde la visión cuantitativa de la investigación pero al mismo tiempo también requiere la aplicación de los parámetros de la investigación explicativa como Quijano (2009) lo deja muy claro en su trabajo. Se requiere seguir profundizando en los resultados de la investigación para entender por qué y cómo ocurre este cambio de paradigmas (Chaves López, 2013) pero esta vez desde la visión de la ética como deber y no sólo como una serie de normas por cumplir cuando se asocia a la moral.

La interpretación de esta modificación en el sentido ético y la pérdida de la connotación de deber, que hace a la ética ser lo que es, fue apoyada por psicólogos que colaboraron con sus explicaciones sobre la interpretación del deber como manifestación práctica de lo ético, vista desde la interioridad humana, y ayudaron a entender el origen de los cambios manifestados en los comportamientos de los estudiantes.

\section{La ética como deber}

Se utiliza la palabra deber para designar a lo que es considerado una obligación, en el sentido de lo que tiene que ver con lo que es apropiado o adecuado hacer en determinado momento y no respecto a lo que la persona quiera hacer o realizar. Es decir, no depende de los gustos o apetencias la realización de una acción, sino del compromiso adquirido, aunque lo ideal sería que en el deber se conjugaran ambas visiones.

El término deber comúnmente se relaciona con la ética y la moral ya que hace referencia a acciones o formas de comportamiento que han sido reflexionadas por el individuo y al mismo tiempo socialmente establecidas y consensuadas como apropiadas o correctas para determinadas situaciones, acciones sin las cuales la sociedad podría en algún sentido perder su orden o su armonía. (Definición $A B C$, s.f.)

La expresión deber muchas veces se entiende en su acepción de obligación, pero la diferencia respecto a esta expresión es que muchas veces se usa como sinónimo, lo cual es un error porque el deber no tiene un sentido forzoso, sino que se expresa en la línea de la responsabilidad y el compromiso adquirido con libertad y voluntariedad. En otras palabras, el deber se corresponde con una acción que una persona puede dejar de hacer, pero que ha elegido hacerla porque considera que eso es lo que le concierne realizar. En la obligación, en cambio, como situación forzosa, la persona no puede elegir y es irrelevante si está o no de acuerdo con la situación planteada o con el hecho a considerar.

Otra distinción esencial es que el deber aparece como uno de los medios que una comunidad tiene para organizarse y establecer un orden social (Definición $A B C$, s.f.), pero sobre todo la más determinante es la acepción que hace relación a las cuestiones relativas a la subsistencia de la especie y en cuanto al orden para evitar que la sociedad caiga en caos (desorden). Es decir, el deber se interpreta como un medio para establecer y sostener la armonía en una comunidad. 
Además, lo ético como deber, no como obligación, está relacionado íntimamente con las responsabilidades y con el sentido común y como tal, esas responsabilidades, hacen parte del derecho y muchas de ellas están determinadas por leyes (por ejemplo, las responsabilidades alimenticias de los padres para con los hijos). Ahora bien, el deber (a diferencia de la obligación) supone algún tipo de beneficio para la personal o para la sociedad y este beneficio es, de alguna manera, evidente.

Pero esta connotación no presupone que el deber esté exento de esfuerzo. Por ejemplo, estudiar implica esfuerzo y gasto de energía y esto no siempre es agradable ni bien recibido y de ahí que se perciba el estudio como una obligación poco grata, pero precisamente para controlar el impulso de no esforzarse existe el deber.

Ahora, del término deber pasamos al término deberes y siempre que se habla de estos se hace referencia a algún tipo de obligación de orden moral, económica, social o política.

Esta acepción de deberes tiene que ver con las actividades, los actos y las circunstancias que implican una determinada obligación moral o ética. Generalmente, los deberes se relacionan con determinadas actitudes que todos los seres humanos, independientemente de su origen, etnia, edad o condiciones de vida se obligan a cumplir para asegurar al resto de la humanidad la posibilidad de vivir en paz, con dignidad y con ciertas comodidades. Los deberes son, entonces, uno de los puntos más importantes de todos los sistemas de leyes y de constituciones nacionales porque tienen que ver con lograr formas comunitarias de convivencia y por lo tanto sociedades más equilibradas en donde todos acceden del mismo modo a sus derechos pues asumen sus deberes (Definición $A B C$, s.f.)

Los deberes pueden estar explícitamente establecidos en una sociedad o por el contrario darse en forma implícita y el cumplimiento de estos se manifiesta en el mejoramiento de las condiciones óptimas mínimas para el desarrollo de una determinada sociedad. En otras palabras, entre más se cumplan las obligaciones más desarrollada cívicamente, y por ende en otros aspectos, lo será esa sociedad.
Entonces, como conclusión de esta reflexión: los deberes son personales, de libre y voluntaria realización, por ejemplo, cumplir con los compromisos, pero que hay que hacerlos si queremos vivir en armonía con nuestra conciencia. Por el contrario, los deberes (como obligaciones) están referidos a la visión social de la convivencia y se viven en las costumbres específicas de cada comunidad.

\section{Conciencia del deber en los estudiantes}

A través de los talleres realizados en la cátedra de Ética profesional jurídica se evidencia un desconocimiento, prácticamente general, de la relación entre ética y deber y del cumplimiento de éste como manifestación práctica del sentido ético.

Las respuestas de los estudiantes muestran que un $80 \%$ de ellos respecto a la pregunta: “ $¿$ Considera que el estudio es un deber, por qué?”, manifestaron su posición asociándola con la obligación de estudiar porque no les queda otra alternativa "para ser alguien en la vida". Pero al repreguntar: “¿Qué significa 'ser alguien en la vida?"', no encuentran la expresión precisa para dar unas razones concretas.

Estas son algunas de sus respuestas:

- "Tengo que pasar el semestre, esa es mi obligación".

- "No puedo fallar a las expectativas de mis papás, pues ellos esperan que me gradúe".

- "No tengo otra alternativa, como sea tengo que pasar la materia".

- "El deber no tiene que ver con la ética, pues deber significa obligación, o sea que yo tengo la obligación de estudiar para ser alguien en la vida".

En otro aparte de estos talleres (Derecho, 2013, p. 3) se propuso como ejercicio de pensamiento la posibilidad de retirar de los Reglamentos de las Instituciones los apartes que hacen mención a los derechos y dejar únicamente los que se refieren a los deberes. La reacción fue unánime y sin mediar reflexión:

- "Eso es imposible, pues la universidad se convertiría en una tiranía".

- "Se acabaría la universidad pues si no hay derechos esto sería un caos".

- “Quiere que la Comisión internacional de Derechos Humanos lo investigue, profesor?” 
- "Entonces, si algo afecta mis derechos ¿no tengo la posibilidad de reclamar?”

Se reformuló la cuestión en estos términos: todos los estamentos de la Institución cumplen sus deberes porque ese es su compromiso; entonces, ¿cómo sería la vida universitaria? Esta reformulación no cambió la posición general de considerar que sería imposible la actividad académica porque:

- "No habría posibilidad de exigir mis derechos".

- "Cada quien trabajaría sin tener en cuenta a los demás".

- "No habría a quien acudir en caso de alguna reclamación".

Prácticamente ninguno de los estudiantes asocia la palabra deberes en su relación a derechos, sino que la interpreta referida a obligaciones, con el entorno semántico de carga que conlleva y, por supuesto, nuestros estudiantes lo menos que quieren es asumir una responsabilidad, es decir una carga. Quieren graduarse sin que esto signifique estudiar y esforzarse. Para ellos, la obligación que tienen es la de terminar los estudios, sin que esto implique el deber de estudiar y prepararse.

Para este punto es necesario destacar que el deber es la cara opuesta del derecho, pero asimismo son íntimos aliados dado que para disponer de determinados derechos deberemos cumplir una serie de deberes. (Definición $A B C$, s.f.)

Al cumplimiento del deber, como expresión práctica de la ética, estamos llamados siempre, porque aunque lo que hay que hacer lo mande una normativa vigente, una costumbre, una norma religiosa o un mandato moral, somos nosotros los que aceptamos cumplir porque consideramos que es lo que hay que hacer. No por miedo al castigo sino porque nuestra conciencia así nos lo hace ver pues hemos superado los niveles pre convencionales y convencionales de la conciencia (Kohlberg, 1992, p. 202) y actuamos no por miedo al castigo o porque existan unas normas que así nos obligan sino que hemos llegado al nivel pos convencional y actuamos porque así debe ser y "adoptamos una perspectiva socio moral que idealmente todos los seres humanos deberíamos adoptar hacia otros como personas libres, iguales y autónomas". (Ramírez Garcia, 2001, p. 57)
El punto cumbre de la actividad mencionada se dio cuando se les explica a los estudiantes el sentido del ejercicio, después de obtener con dificultad su atención porque, saliéndose del ejercicio de pensamiento, muchos de ellos consideran que "si eso lo dijo el profesor en clase es por algo" y entonces pueden "perder sus derechos" y hay que pelear y protestar y exigir.

El sentido es el siguiente: si todos los miembros de cualquier Institución, por encima de rangos o instancias, cumplimos con nuestros deberes estamos al mismo tiempo concediendo y valorando los derechos de los demás. Los problemas se dan, y por ende la exigencia de los derechos, cuando alguien, en algún momento no cumple con su deber como responsabilidad que le corresponde realizar. En este sentido no porque exista de por medio un contrato de trabajo, sino porque la persona lo considera un deber ético. En otras palabras porque nos movemos en el nivel pos convencional, en las palabras de Laurence Kohlberg ya mencionadas.

Uno de los puntos más importantes dentro del desarrollo de los talleres mencionados se encuentra cuando "instintivamente" los estudiantes enlazan los deberes con la noción de derechos. Los psicólogos afirman respecto a esta condición "instintiva" diciendo que el ser humano ha sido educado para responder a lo que él, o su entorno familiar o social, considera se le debe (derecho) y no como su deber (responder a otros).

- "Si yo cumplo mis deberes estoy respetando el derecho de los demás".

- "Los demás deben respetar mis derechos".

- "Yo tengo derecho...".

La influencia social que ha endiosado los derechos y los hace ver como la máxima aspiración del ser humano y de la sociedad donde vive ha hecho perder el sentido ético y axiológico del deber. Encontramos "derechos" donde quiera que nos movemos y la invitación a "hacer respetar los derechos" suena por doquier, pero prácticamente no se habla del deber o de los deberes, ni se hace la distinción entre lo personal y lo social (Derecho, 2013, p. 4).

Esta influencia ha marcado a nuestros estudiantes quienes consideran que el mundo está obligado a garantizar y a salvaguardar sus "derechos" sin que de parte de ellos haya una correspondencia en el cumplimiento de sus deberes. Si bien es cierto que 
deberes y derechos se relacionan y son de igual manera esenciales para que los miembros de la sociedad puedan convivir en paz, de manera ordenada, organizada y civilizada, esto no se da de manera paralela sino como fruto de una relación directamente proporcional: a más deberes... más derechos. O puesta la expresión en la línea de esta investigación: a más derechos... más deberes. Entender la contraposición (pero al mismo tiempo la relación) entre deberes - derechos debería ser inherente a todos y cada uno de los miembros que forman una sociedad.

Pero esto no es así y el resultado de los talleres muestra otra visión y consideración por parte de los estudiantes:

- "El deber hay que evitarlo, pero hay que exigir los derechos".

- "Yo tengo el derecho a estudiar, lo consagra la Constitución, y por tanto el derecho de graduarme. La universidad tiene el deber de graduarme".

- "En mi casa siempre me han dicho que debo hacer respetar mis derechos".

- "Yo pagué la matrícula, tengo derecho a pasar la materia”.

A tenor de los resultados de los talleres vemos cómo el deber ha perdido su connotación ética y su razón de ser como fundamento en la generación de una persona consciente de su realidad de ser humano y con criterio para su actuar (Derecho, 2013, p. 4)

\section{Conciencia: relación entre los deberes y los derechos}

Habrá conciencia de la relación entre deberes y derechos cuando en un determinado ordenamiento jurídico, los individuos que forman parte de él sepan perfectamente cuáles son sus deberes y cuáles sus derechos en función de la normativa que los rige. Sin esta conciencia es factible que esos derechos y deberes queden inmortalizados en un documento escrito y se queden en ello nomás, perdiendo su conexión y el enlace que los unifica. (Definición ABC, s.f.).

A lo largo de la investigación se descubre que los estudiantes reconocen la existencia del deber pero siempre en relación consigo mismo (tengo el deber de estudiar) pero no en relación con los demás (cumplo mi deber como un medio para hacer mejor la vida en sociedad). Es más, cuando se plantea el tema, los deberes, siempre lo consideran asociado a lo que los demás tienen que hacer por ellos y no al contrario.

Retomando el ejercicio de pensamiento en el que la propuesta es quitar los derechos de los Reglamentos institucionales, no perciben conscientemente que si alguien tiene un deber para con otro y lo cumple, entonces, no sería necesario que la otra parte reclame nada. Es decir, se le está garantizando su derecho porque los demás cumplen con su deber. Los estudiantes no establecen una conexión directa entre deber y derecho. Para ellos sólo son importantes los derechos a "los que tienen derecho". Pero esta concepción no contribuye de manera directa y efectiva a disponer una convivencia armónica y pacífica a nivel social, pues todos reclaman sus derechos, pero al no balancearlos con los deberes se genera un desequilibrio que afecta la relación.

Siguiendo a Sócrates la única opción de fomentar un cambio en la conciencia de las personas es a través de la educación, en sus propias palabras: "el malo es malo por ignorante". Se requiere, entonces, para cambiar esta situación la necesaria presencia de tres elementos:

- El conocimiento de la norma: si alguien desconoce tal o cual norma será realmente imposible que la cumpla o que la observe.

- Se requiere un movimiento social que perdure a través del tiempo y que exija el cumplimiento efectivo de la norma.

- La presencia de organismos que se ocupen de vigilar el cumplimiento de las normas. (Definición ABC, s.f.).

El filósofo alemán Emmanuel Kant (1770) propone una ética formal, en contraposición a las éticas materiales, que tiene relación directa con el deber. Y a partir de esta relación la ética formal se manifiesta a través de imperativos categóricos, es decir, la realización de aquellas acciones mandadas por el deber sin preocupación alguna por las consecuencias, sino hechas por el solo respeto hacia el deber. Como consecuencia, quien así lo realiza es un hombre porque puede dominarse a sí mismo; en otras palabras, será un hombre libre, autónomo. Para que esta relación pueda darse, el énfasis se coloca en las decisiones éticas que tienen como fin último el cumplimiento del deber y esto es lo que la diferencia de otro tipo de consideración ética. 
La conciencia como manifestación de la relación entre deberes y derechos está claramente determinada en Kant y en su libro la Crítica del juicio así lo expresa, por eso su propuesta ética promueve la libertad yla dignidad de todos los hombres por sobre todas las cosas. Y la libertad y la dignidad hacen parte de la conciencia, es decir del saber que soy un ser con deberes y derechos.

Kant sostiene que lo objetivamente bueno es una buena voluntad, el resto de las cosas que normalmente consideramos valiosas como ser (inteligencia, valor, riqueza) no lo son e incluso pueden volverse peligrosas para el hombre cuando lo que lo mueve a actuar es una voluntad torcida (Kant, 1999, p. 215). La buena voluntad es la disposición para el cumplimiento del deber; esto significa, de acuerdo a lo que venimos exponiendo, que quien actúa con buena voluntad es un hombre ético porque cumple con su deber.

De acuerdo con Kant, el hombre posee razón e instinto $\mathrm{y}$ ambos aspectos interrelacionados son lo que le garantiza la supervivencia como individuo y como especie. La razón práctica, es decir saber qué es lo que se debe hacer en el momento adecuado, no sólo tiene una función teórica sino que también actúa de forma práctica y tiene como objetivo buscar el bien moral. En otras palabras, hacer del individuo un ser ético, es decir una persona cumplidora de su deber. Ahora bien, en sus propias palabras: "Si el fin del hombre fuese justamente la felicidad la naturaleza no nos hubiese dotado de una razón práctica que elabore juicios que no nos lleven a la felicidad, entonces, es un hecho que el hombre fue dotado de razón por un fin mucho más alto que la felicidad" (Kant, 1999, p. 215).

Para Kant, el fin de la existencia del hombre no es la felicidad sino el cumplimiento del deber: hacer lo que se debe hacer. Esto responde claramente a la situación que viven los estudiantes cuando por evitar esfuerzo, trabajo, dedicación que implique sacrificio, prefieren "pasar" el semestre a través de otros medios que les permita conseguir el mismo objetivo, sin importar su implicación ética ni moral.

Los talleres realizados nos llevan a la siguiente conclusión, en palabras de los mismos estudiantes, "entonces, si el objetivo se consigue, ¿por qué tiene que ser con esfuerzo y sufrimiento? Lo que interesa es tener el título porque el conocimiento se adquiere por la experiencia. ¿Ética? ¿Eso qué significa cuando vemos quelos que deberían darnos ejemplo, nuestros dirigentes políticos, no viven éticamente, ni cumpliendo su deber y viven bien? ¿Por qué no se debe hacer trampa? Y no nos sirve como respuesta un 'porque no debe ser así.

Esperan encontrar una razón que vaya más allá del remitirse a la conciencia o a la condición humana; quieren colocar en el mismo plano lo contingente y lo necesario, lo transcendental y lo que no lo es. Eso es imposible de conciliar.

"Al acto de quebrar ciertas reglas se le denomina viveza" (Espinoza, 2009, p. 28); la recompensa por estos actos es la satisfacción propia e inmediata de lo que se ha hecho, sin trascendencia ni cargo de conciencia. El desconocimiento de la relación entre ética y deber es total y las consecuencias las experimentamos permanentemente.

Pero, la misión de la cátedra no es únicamente la actividad académica y menos aún cuando formamos a quienes nos reemplazarán en el futuro y serán los encargados de regir los destinos de la sociedad, por eso tiene sentido la insistencia en la formación moral de los estudiantes que los lleve a una reflexión ética y a la formación de una conciencia que les permita cumplir con su deber como un imperativo categórico: las cosas deben ser como deben ser porque no hay otra forma de ser.

\section{Conclusiones}

Existe una general predisposición a la inobservancia de las normas porque se ha perdido la relación existente entre lo ético y el deber. Desde pequeños se nos ha educado, no en el esfuerzo y el sacrificio, sino en la comodidad y la búsqueda de la forma fácil de vivir, sin compromiso ni responsabilidades. Desde la familia, la formación recibida tiene que ver con la exigencia de los derechos y únicamente con esto. Lo ético se pierde con tal de vivir con el menor esfuerzo posible.

--"La formación humana y más aún en las actuales circunstancias del país y del mundo con toda su problemática social y de convivencia, desde la violencia hasta la corrupción, desde el tráfico de estupefacientes hasta los mismos problemas ambientales, se solucionarían si se mejorará la calidad de vida en especial en la formación en ética: valores morales y ciudadanos, con su carga de deber y responsabilidad"--. (Espinoza, 2009, p. 29) 
Como no hay conciencia en los estudiantes de la relación entre ética y deber, --"se suele escuchar frecuentemente entre los estudiantes que justifican sus conductas inapropiadas (hacer trampa en los exámenes, suplantar, plagiar los trabajos, sobornar, chantajear, competir deslealmente) diciendo que se trata de simples 'ayudas educativas', convirtiéndose en prácticas cotidianas entre ellos"--. (Espinoza, 2009, p. 29)

La dificultad para relacionar ética y deber trae como consecuencia para los estudiantes, y para la sociedad, "el facilismo, la ley del menor esfuerzo, la mediocridad, la irresponsabilidad, la falta de compromiso, la falta de una verdadera vocación profesional y por supuesto, como consecuencia el abordar la profesión como un simple conjunto de habilidades y destrezas sin compromiso" (Espinoza, 2009, p. 30) personal y social que signifique para las nuevas generaciones una oportunidad de desarrollo material y de mejoramiento en las relaciones interpersonales y la convivencia social.

La exigencia, entonces, es retomar la relación que se ha perdido, la ética sólo puede comprenderse desde el deber y el deber, como la acción que se realiza, sólo puede tener sentido cuando tiene su base en la conciencia del individuo, que se conoce a sí mismo (Sócrates) y que se forma para el bien.

\section{Referencias}

Chaves López, J. L. (2013. agosto). Las facultades de Derecho y

el sentido ético. Revista Tiempos Nuevos, 20, 53 - 61.

Definición ABC (s.f.) Consultado 23 de marzo de 2014, http:// www.definicionabc.com/social/deber

Derecho, E. D. (2013, Noviembre 10). El sentido ético del deber. (J. L. Chaves, Interviewer) Pasto.

Espinoza, M. (2009). La viveza desde una óptica ética. Pasto: I.U. CESMAG.

Chaves López, J. L. (2012). Ética... para qué? Taller. Pasto.

Institución Universitaria CESMAG, C. D. (2005). Reglamento estudiantil. Pasto: I.U. CESMAG.
Kant, E. (1999). Crítica del juicio (Trad. de Manuel García Morente). Madrid: Espasa - Calpe.

Kohlberg, L. (1992). Psicología del desarrollo moral. Bilbao: Desclée De Brouwer.

Quijano, A. J. (2009). Guía de Investigación cuantitativa. Pasto: IUCESMAG.

Ramírez Garcia, G. A. (2001). Manual para el acompañamiento familiar. Medellin: Alvaro Trujillo.

Savater, F. (1991). Ética para Amador. Barcelona: Ariel. 